\title{
nature
}

nanotechnology

\section{Conferences in the nanoworld}

\author{
Scientific meetings and conferences come in all shapes and size, and love them or loathe \\ them, they have an important role to play in all areas of science.
}

Later this month researchers from all over the world will gather in the upmarket Keystone Resort and Conference Centre in Colorado for the third International Conference on Nanoscience + Technology $(\mathrm{ICN}+\mathrm{T})^{1}$. The organizers expect $600-700$ people to attend, which is not large by the standards of many conferences. Indeed, it is also quite small compared with some nano-events, such as the businessoriented NSTI Nanotech 2008 meeting in Boston $^{2}$ - which boasted 4,000 attendees and 400 exhibitors in June - and the massive 'nano tech' events that draw huge numbers of the general public to the Tokyo Big Sight every February ${ }^{3,4}$. However, compared with other nanoconferences, ICN+T is emerging as the foremost conference that covers most areas of research within nanoscience and technology.

The ICN+T has its origins in a meeting in Basel in 2006 that brought two different conference series together to celebrate 25 years of the scanning tunnelling microscope (STM) and 20 years of the atomic force microscope $(\mathrm{AFM})^{5}$. The second meeting in the series was held in Stockholm last year. This year's meeting in Keystone will cover six areas: molecular and nanoelectronics; nanobiology, nanomedicine and nanofluidics; nanoscale measurement of novel materials; nanosystems, nanomechanics and nano-optics; scanning probe microscopy and instrumentation; and spintronics and nanomagnetism.

The ICN+T in Keystone will actually be smaller than the meeting in Basel - which was attended by some 1,600 delegates - but size isn't always everything in the nanoworld. For instance, in a recent post on his blog, nanoscale views, Doug Natelson of Rice University described how he had just attended "practically the perfect scientific meeting - about 80 attendees, a mix of theorists and experimentalists, and all the talks were very good and pitched at the right level"6. The meeting in question was the snappily titled Electronic Structure and Processes at Molecularbased Interfaces (ESPMI-08 for short) at Princeton University, and the only downside was a one-second power glitch that had local researchers scurrying back to their labs to check their vacuum systems. That is unlikely to happen in Keystone.

\section{Everyone hopes that one day they will experience something like the 'Woodstock of physics'.}

At the opposite end of the spectrum are the massive annual and twice-yearly meetings organized by the big US societies - the March meeting of the American Physical Society (APS) and the Spring and Fall meetings of the American Chemical Society and the Materials Research Society. With their dozens of parallel sessions, and their seemingly non-stop procession of 12-minute talks, these meetings are not for the fainthearted, but they play a valuable role in exposing students to the world of research, warts and all.

In some areas of nanoscience and technology, notably semiconductor devices, conferences such as the International Electron Devices Meeting are still the place to go to hear the latest results. At most conferences, however, the results on display will have already been published or accepted for publication, although all attendees harbour the hope that one day they will experience something like the 'Woodstock of physics' (when a session on cuprate superconductors at the 1987 APS meeting in New York started at 7.30pm and did not end until 3.15am the following morning).

Of course, the popular history of nanotechnology actually starts with a talk at a previous APS meeting in New York - Richard Feynman's famous "There's plenty of room at the bottom" lecture in $1959^{7,8}$. More important, if not so well known, was an early workshop on the STM in Oberlech in Austria in 1985 (at which "devices such as the AFM have their roots [...] and during the last night of the workshop the Alps were buzzing with crazy new ideas for using such microscopes"5), and the first STM conference at Santiago de Compostela in Spain a year later.

In time-honoured style I have reached the end of this article without covering a very important conference topic - how to give a good conference talk. I could exceed my allotted slot by listing various do's and don'ts, but the golden rule when giving talks is to finish on time, so I will refer you to previous articles on this topic written by colleagues on other Nature journals ${ }^{9,10}$. The secret, they conclude, is to rehearse and to always remember that you are speaking for the audience and not to yourself. Thank you.

\footnotetext{
References

1. www.icnt2008.us

2. www.nsti.org/Nanotech 2008

3. www.ics-inc.co.jp/nanotech/en/show.html

4. Sandhu, A. Nature Nanotech. 2, 195 (2007)

5. Gerber, Ch. \& Lang, H. P. Nature Nanotech. 1, 3-5 (2006).

6. nanoscale.blogspot.com (12 June 2008).

7. Feynman, R. P. Eng. Sci. 23, 22-36 (February 1960).

8. Toumey, C. Eng. Sci. 68, 16-23 (June 2005).

9. Nature Meth. 5, 371-372 (2008).

10. Nature Phys. 4, 429 (2008).
} 